\title{
Metodologías para la detección de SARS-CoV-2 y análisis de carga viral mediante RT-PCR cuantitativa
}

Carolina Jaquenod De Giusti "; Mauro Montanaro 2; María Victoria Mencucci ${ }^{3}$; Romina Canzoneri ${ }^{4}$; Alejandro Orlowski ${ }^{1}$, Marianela Santana ${ }^{2}$; Erica Pereyra ${ }^{1}$; Mauricio Kraemer ${ }^{3}$;

Sabrina María Luisa Lavarías 5; Verónica Moscoso 2; Noelia Costantini ${ }^{1}$; Flavio Francini ${ }^{3}$; Horacio Garda 2; Nicolás Pedríni 2; María González Baro 2; Martín Vila Petroff '; Alejandro Aiello 1; Martín C. Abba ${ }^{4,6}$

${ }^{1}$ Centro de Investigaciones Cardiovasculares (CIC-CONICET-UNLP), ${ }^{2}$ Instituto de Investigaciones Bioquímicas La Plata (INIBIOLP-CONICET-UNLP), ${ }^{3}$ Centro de Endocrinología Experimental y Aplicada (CENEXA-CONICET-UNLP), ${ }^{4}$ Centro de Investigaciones Inmunológicas Básicas y Aplicadas (CINIBA-UNLP), 5 Instituto de Limnología de La Plata (ILPLA-CONICET-UNLP), 6 mabba@med.unlp.edu.ar

Resumen. En diciembre de 2019, se produjo un nuevo brote de enfermedad por coronavirus (COVID-19) en Wuhan, China. El síndrome respiratorio agudo severo-coronavirus-2 (SARS-CoV-2), que es el séptimo coronavirus conocido que infecta a los humanos, es altamente infeccioso y se ha expandido rápidamente en todo el mundo desde su descubrimiento. El diagnóstico de la infección por SARS-CoV-2 se basa en la detección del genoma viral (ARN) a través de técnicas de biología molecular. Con este fin, se extrae el ARN total para su posterior detección mediante PCR cuantitativa en tiempo real (RT-qPCR). Las pruebas cuantitativas de ácidos nucleicos se han convertido en el "estándar de oro" para el diagnóstico y guía en la toma de decisiones clínicas. Sin embargo, los ensayos de RT-qPCR dirigidos al SARS-CoV-2 tienen varios desafíos, especialmente en términos de diseño de cebadores / sondas y de desarrollo de metodologías que permitan estimar la carga viral en pacientes con diagnóstico de COVID-19.

Palabras clave: SARS-CoV-2; COVID-19; detección; carga viral; PCR cuantitativa 
SARS-CoV-2 diagnosis and viral load methods based on quantitative RT-PCR

Abstract. In December 2019, a new coronavirus disease (COVID-19) outbreak occurred in Wuhan, China. Severe acute respiratory syndrome-coronavirus-2 (SARS-CoV-2), which is the seventh coronavirus known to infect humans, is highly contagious and has rapidly expanded worldwide since its discovery. Quantitative nucleic acid testing has become the gold standard for diagnosis and guiding clinical decisions regarding the use of antiviral therapy. Total RNA is purified for subsequent SARS-CoV-2 detection by a real time quantitative RT-PCR (RT-qPCR). However, the RTQPCR assays targeting SARS-CoV-2 have a number of challenges, especially in terms of primer / probe design and in the development of methodologies to estimate viral load in patients diagnosed with COVID-19.

Keywords: SARS-CoV-2; COVID-19; detection; viral load; quantitative PCR

\section{Contexto y relevancia del desarrollo}

En diciembre de 2019 un nuevo betacoronavirus provisionalmente llamado 2019nCOV y subsecuentemente designado SARS-CoV-2, causó una aglomeración de infecciones respiratorias en Wuhan, China. Este nuevo virus causa la enfermedad por COVID-19 y se ha propagado de forma exponencial en todo el mundo (Lupia et al., 2020). Al 7 de septiembre del 2020, la OMS ha confirmado alrededor de 27 millones de casos distribuidos en alrededor de 200 países, con 900.000 muertes. Argentina tiene cerca de 500.000 casos confirmados desde el inicio de la pandemia de los cuales 290.000 casos han aparecido en el transcurso del último mes (agosto de 2020). A pesar de que la gran mayoría de los pacientes (85\%) presenta un cuadro leve que no requiere tratamiento, se estima que alrededor del $15 \%$ de los infectados requiere hospitalización, y que dos tercios de estos pacientes necesitan ventilación 
mecánica dentro de las primeras 24 horas de ser admitidos (Mahase 2020). Tal situación representa un gran reto para las unidades de cuidados intensivos y la mayoría de los sistemas de salud a nivel mundial, ya que la transmisión del virus es bastante rápida y no es posible atender a todos los pacientes que requieren cuidados intensivos. El SARS-CoV-2 parece ser más infectivo al momento de la aparición de los síntomas, disminuye hasta casi cero después de aproximadamente 10 días en pacientes leves a moderados y 15 días en pacientes graves, críticos e inmunodeprimidos (Rheec et al., 2020). El SARS-CoV-2 parece tener una dinámica de transmisión similar a la influenza, que también es contagiosa antes y varios días después de la aparición de los síntomas (Rheec et al., 2020).

A pesar de que las personas más susceptibles a desarrollar un cuadro grave de COVID-19 son adultos mayores o personas con comorbilidades (enfermedades cardiovasculares, diabetes, cáncer e inmunosupresión), no existen hasta el momento marcadores con valor pronóstico. Esta situación deviene en una alta ocupación de servicios de urgencias y camas de hospitalización, muchas veces sin necesidad. Un posible biomarcador de la severidad de la enfermedad es la carga viral del SARS-CoV-2 al momento de la hospitalización. Estudios realizados durante la pandemia por SARS-CoV en 2003, causada por un virus estrechamente relacionado con SARS-CoV-2 sugieren que la viremia inicial está asociada con un peor pronóstico (Chu et al., 2004). Consistentemente, en un trabajo publicado recientemente, se ha demostrado una correlación lineal entre la carga viral y 
Innovación y Desarrollo Tecnológico y Social (2020) 2 (2): 1-14- Número especial COVID-19

diferentes biomarcadores de severidad de enfermedad pulmonar en pacientes infectados con SARS-CoV-2 (Liu et al., 2020). La carga viral de SARS-CoV-2 detectada en los pacientes también se correlacionó intensamente con el índice del síndrome de distrés respiratorio agudo (ARDS) expresado como el cociente entre la presión parcial de oxígeno arterial y la fracción de oxígeno inspirado (PaO2/FiO2) (Liu et al., 2020).

\section{Objetivos y grado de pertinencia del desarrollo}

Lo anteriormente expuesto hace imperativa la necesidad de desarrollar un método que permita identificar de forma cuantitativa el riesgo que tiene cada paciente de desarrollar o no una enfermedad grave, con el objetivo de optimizar la atención médica y de esta forma destinar los recursos hospitalarios únicamente a las personas susceptibles al desarrollo de complicaciones.

De esta manera el eje central del proyecto consiste en el desarrollo de un sistema RT-qPCR para la determinación de la carga viral del SARS-CoV-2 a partir de muestras de hisopados nasofaríngeos en pacientes con diagnóstico confirmado de COVID-19. En primer lugar, dicho desarrollo se pondrá a disposición del sistema sanitario provincial y nacional a la manera de un servicio tecnológico brindado por la Facultad de Ciencias Médicas de la UNLP. En segundo lugar, se evaluará la posibilidad de producción y distribución del sistema de detección de carga viral a todo laboratorio 
de salud pública que desee evaluarlo, previa autorización y certificación por las instituciones involucradas.

\section{Detección y determinación de la carga viral del SARS-CoV-2}

EI SARS-CoV-2 se clasifica dentro del género Betacoronavirus y posee un tamaño de aproximadamente 50 a 200 nm de diámetro. Es un virus con envoltura en la cual se insertan las proteínas virales S, E y M las cuales otorgan la morfología en espículas características de esta familia. Dentro de la envoltura se encuentra la nucleocápside con estructura helicoidal, formada por el genoma viral al que se encuentran unidas múltiples copias de la proteína N. El genoma viral está constituido por una cadena simple de ARN de polaridad positiva de $29 \mathrm{~kb}$ de longitud. A partir de esta molécula se traducen al menos 16 proteínas no estructurales (ORF1a/ab) y 4 proteínas estructurales (S, E, M y N), necesarias para cumplir el ciclo de replicación completo. El 12 de enero de 2020, se publicó el genoma del SARS-CoV-2 aislado a partir de una muestra de un paciente afectado por neumonía en la ciudad China de Wuhan (wuhCor1) (Figura 1). Dicho genoma y las secuencias subsiguientes fueron compartidas a través de la plataforma provista por Global Initiative on Sharing All Influenza Data (GISAID, http://www.gisaid.org/). La secuenciación del genoma permitió el rápido desarrollo de sistemas de diagnóstico basados en la RT-PCR cuantitativa en tiempo real (RT-qPCR). A partir del conocimiento de la secuencia completa del genoma viral, se pudieron diseñar los ensayos utilizados para su 
detección en los Institutos de Salud de China (CN-CDC), Japón (NIID), Alemania (EUDrosten), Francia (Pasteur Institute) y Estados Unidos (CDC) (Figura 1). Recientemente la Administración Nacional de Medicamentos, Alimentos y Tecnología Médica (ANMAT) de Argentina informó la lista actualizada de ensayos comerciales de uso in vitro para detección o diagnóstico directo de SARS-CoV-2 que se encuentran autorizados en el marco de la emergencia sanitaria ante dicha administración nacional (https://www.argentina.gob.ar/noticias/reactivos-covid-19).

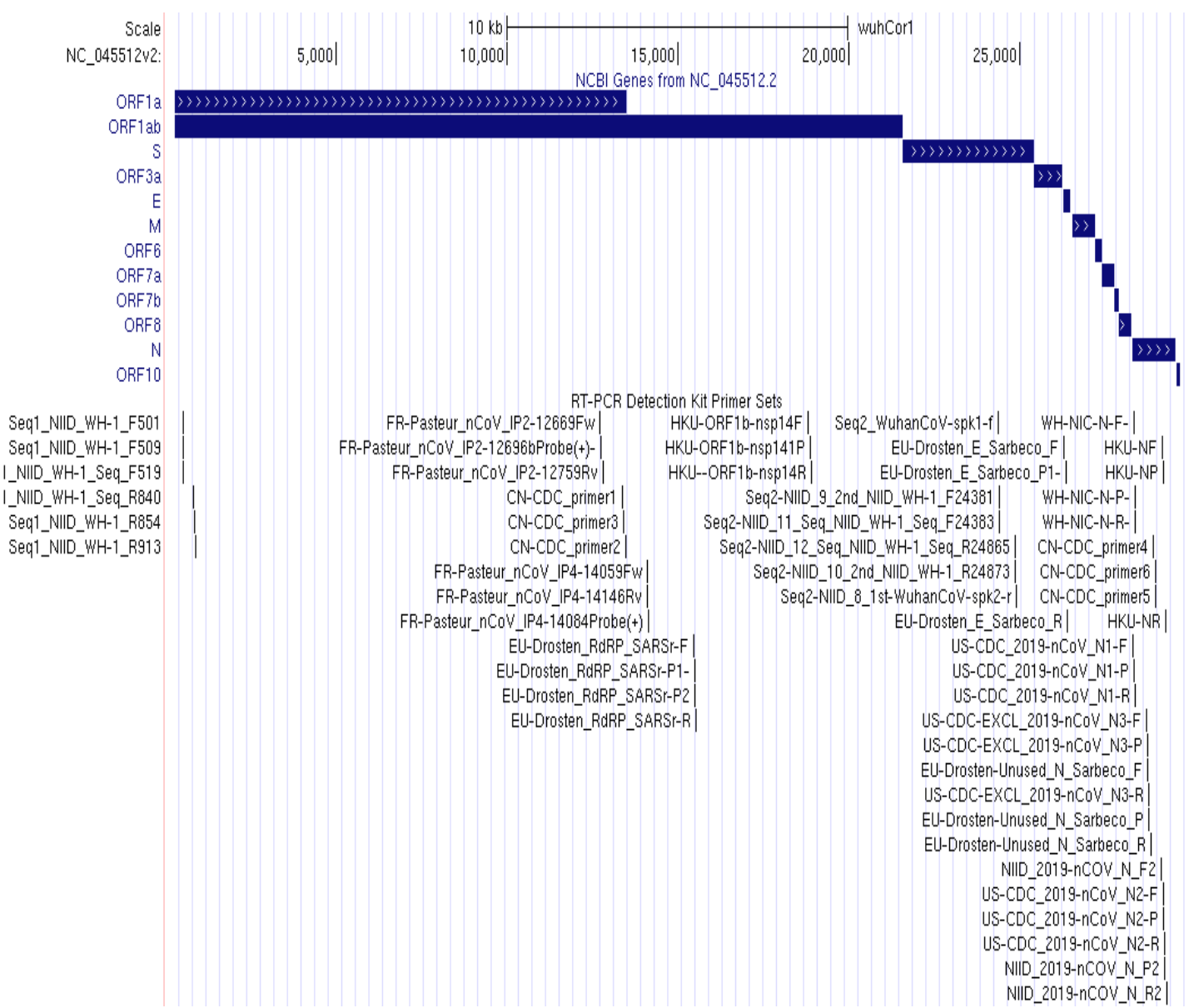

Figura 1. Genoma del SARS-CoV-2 (wuhCor1) con las respectivas secuencias cebadoras y sondas utilizadas para el diagnóstico por RT-qPCR. Imagen obtenida con el UCSC Genome Browser (https://genome.ucsc.edu/). 
Innovación y Desarrollo Tecnológico y Social (2020) 2 (2): 1-14- Número especial COVID-19

Figure 1 (previous page). SARS-CoV-2 (wuhCor1) genome with the respective primer sequences and probes used for diagnosis by RT-qPCR. Image obtained with the UCSC Genome Browser (https://genome.ucsc.edu/).

El diagnóstico de laboratorio de COVID-19 se basa en un resultado positivo de una RT-qPCR que puede involucrar uno o más genes virales y un gen de referencia humano. Las muestras recomendadas para el diagnóstico son muestras del tracto respiratorio tales como hisopados nasofaríngeo y/u orofaríngeo. En los casos que presenten signos o síntomas de infección del tracto respiratorio inferior o frente a la dificultad o imposibilidad de toma de la muestra, se pueden utilizar muestras de esputo, lavado broncoalveolar y/o aspirado endotraqueal. El proceso de diagnóstico comienza con el traslado de las muestras al laboratorio en recipientes apropiados para el transporte de muestras infecciosas (ej.: Sisteg, http://sisteg.com.ar). Estos envases deben ser abiertos dentro de cabinas de seguridad biológica tipo 2 (CSB-II). Independientemente del protocolo de extracción a utilizar, las muestras deben ser mantenidas refrigeradas hasta la extracción y luego deben dejarse templar a temperatura ambiente antes de comenzar el procedimiento. La importancia de la muestra a utilizar radica en seleccionar el mejor material de partida para un mejor aislamiento del ARN viral, por lo que se recomienda la utilización de hisopados nasofaríngeos. El protocolo de extracción se basa en la unión del ARN (tanto viral como humano) a una superficie de sílica con adherencia a este tipo de moléculas, 
seguido de lavados y una elución final. El material genómico aislado debe conservarse $\mathrm{a}-80^{\circ} \mathrm{C}$ hasta su utilización. Este material ya no es infeccioso, pudiendo utilizarse en condiciones de bioseguridad menos estrictas. Los cebadores son componentes fundamentales de un ensayo de PCR y dicha optimización puede ser un proceso complicado que requiere especial atención (Park et al., 2020). En primer lugar, se necesitan cumplimentar las reglas básicas para el diseño de las secuencias cebadoras y sondas, así como para el diseño del control positivo y el gen de referencia a implementar (Bustin and Huggett et al., 2017; Li et al., 2020).

Los sistemas para la detección del SARS-CoV-2 detectan una o más dianas virales en una reacción multiplex que implementa la detección de un transcripto humano (RNasa P, B-actina, GAPDH) como control interno (Figura 2a-c). La detección se basa en la utilización de oligonucleótidos complementarios a los productos de amplificación (sondas) que como producto de la reacción de amplificación liberan fluorescencia, la cual es detectada y cuantificada por el equipo de qPCR. El ciclo al cual la fluorescencia de la reacción (para cada sonda específica para cada producto de amplificación) sobrepasa la fluorescencia basal (umbral o "threshold") es conocido como Ct ("Threshold point" o ciclo umbral). El Ct es un valor definido de forma arbitraria por el usuario, aunque es posible definirlo de forma matemática y es de relevancia porque determina la detección o no del genoma viral. La Figura 2a y b corresponden a una curva de amplificación representativa a partir de la cual es posible determinar el Ct de dos genes virales (Orf1ab y RdRp, respectivamente). Los 
Innovación y Desarrollo Tecnológico y Social (2020) 2 (2): 1-14- Número especial COVID-19

ensayos que implementan la detección de múltiples dianas virales pueden mejorar la sensibilidad evitando falsos negativos. Los genes ORF1ab, E y N están altamente conservados en el subgénero de los Sarbecovirus (incluye SARS-CoV y SARS-CoV-2). Por otro parte, el gen que codifica la ARN polimerasa viral (RdRp) localizado en el ORF1ab se caracteriza por su alta tasa de mutación y recombinación (Li et al., 2020). Por lo tanto, las principales regiones seleccionadas para la detección del SARS-CoV2 se posicionan en regiones con baja tasa de variabilidad, pero específicas de SARSCoV-2.

Nuestro desarrollo consiste en una RT-qPCR absoluta de un solo paso que implementa una curva de calibración y un modelo integrado de análisis para la estimación del número de partículas virales a partir de los valores de Ct de los genes diana. Las curvas de calibración se generan a partir de diluciones seriadas de uno o varios clones plasmídicos previamente construidos con los genes diana virales. Si se grafica el Ct obtenido con respecto a la dilución del número de copias del genoma viral correspondiente se obtiene una curva de calibración (figura 2d) cuya pendiente permite calcular la eficiencia de la reacción de amplificación mediante la ecuación: $E=10^{-1 / m}$ (donde $\mathrm{m}$ es la pendiente de la curva). 


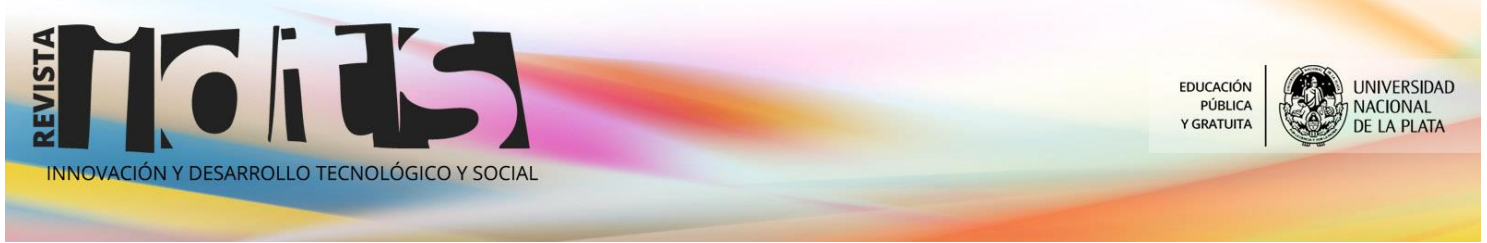

Innovación y Desarrollo Tecnológico y Social (2020) 2 (2): 1-14- Número especial COVID-19

a

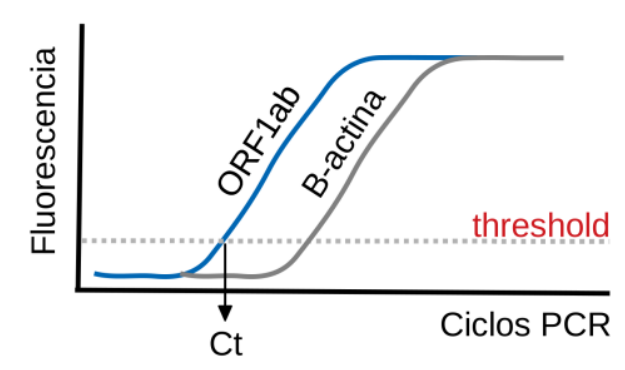

C

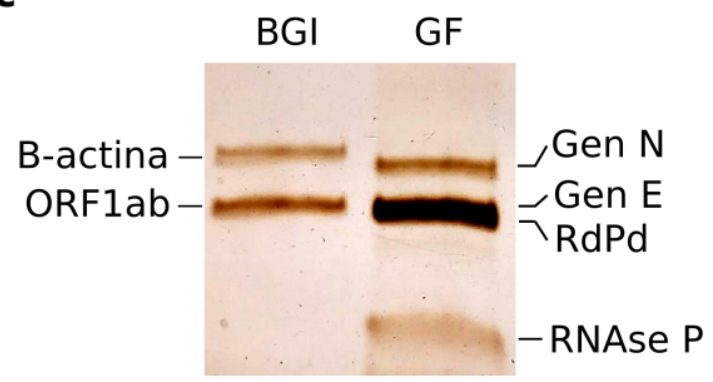

e

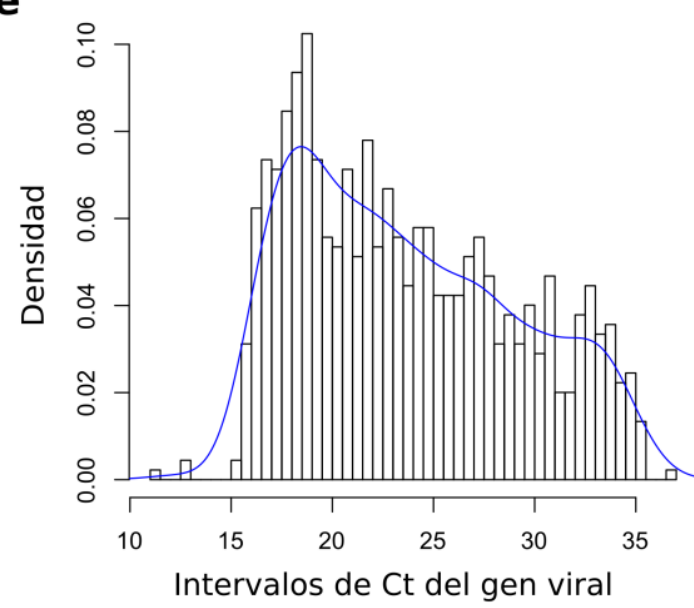

b

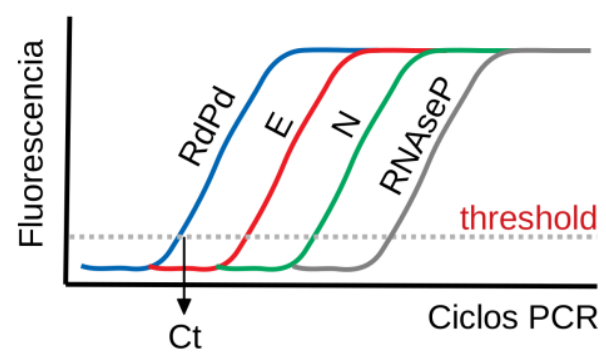

d

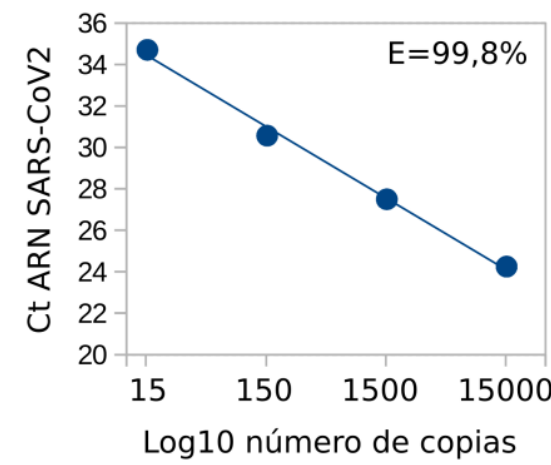

$\mathbf{f}$

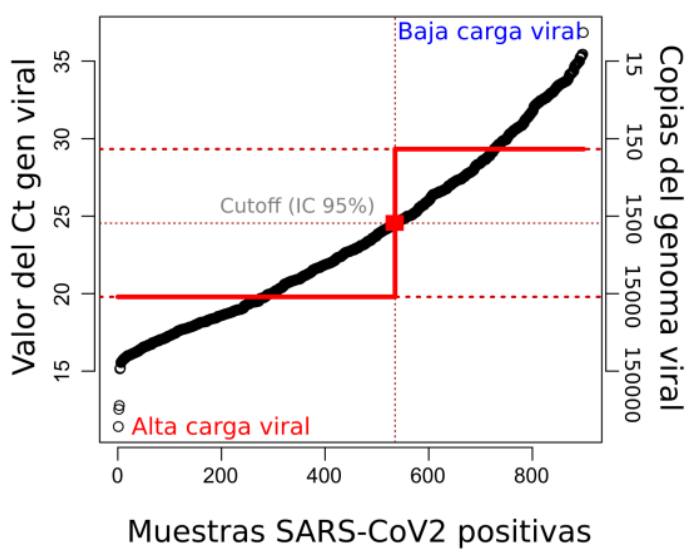

Figura 2. Detección y determinación de la carga viral del SARS-CoV-2. a) Sistema diagnóstico (BGI Real-Time Fluorescent RT-PCR Kit for Detecting SARS-CoV-2) basado en la detección de un gen viral (ORF1ab) y un gen de referencia ( $\beta$-actina). b) Sistema diagnóstico (GeneFinder ${ }^{\mathrm{TM}}$ COVID-19 Plus RealAmp Kit) que se basa en la detección tres genes virales (RdPd, E y N) y un gen de referencia (RNAseP) en reacción multiplex. c) Corrida electroforética en gel de poliacrilamida al 10\% de los productos de RT-PCR de los controles positivos de reacción. d) Curva de calibración para la determinación de la carga viral en función de los valores de ct (número de ciclos de amplificación 
necesarios para alcanzar un umbral de señal fijo) de las reacciones de RT-qPCR. E= Eficiencia. e) Histograma de la distribución de Cts de una diana viral sobre $\mathbf{9 0 0}$ muestras positivas para SARS-CoV-2. f) Modelo integrado para la estimación de la carga viral de SARS-CoV-2.

Figure 2 (previous page). Detection and determination of the SARS-CoV-2 viral load. a) Diagnostic system (BGI Real-Time Fluorescent RT-PCR Kit for Detecting SARS-CoV-2) based on the detection of a viral gene (ORF1ab) and a reference gene ( $\beta$-actin). b) Diagnostic system (GeneFinderTM COVID-19 Plus RealAmp Kit) based on the detection of three viral genes (RdPd, E and N) and a reference gene (RNAseP) in multiplex reaction. c) Electrophoretic run in $10 \%$ polyacrylamide gel of the RT-PCR products of the positive reaction controls. d) Calibration curve for the determination of the viral load as a function of the Ct values (number of amplification cycles necessary to reach a fixed signal threshold) of the RT-qPCR reactions. E = Efficiency. e) Histogram of the Cts distribution of a viral target on 900 positive samples for SARS-CoV-2. $f$ ) Integrated model for the estimation of the SARS-CoV-2 viral load.

Es de importancia conocer la eficiencia real de la reacción y tomarla en cuenta al momento de calcular la carga viral, ya que al tratarse de un incremento exponencial en el número de copias se pueden sobreestimar o subestimar dichos niveles. Por lo cual no solo se evaluará el comportamiento de la curva en distintos equipos de qPCR sino también en distintos rangos de cargas virales en función del tipo de muestras clínicas (ej.: hisopados nasofaríngeos, 500 - 100.000 copias/mL) (Pan et al., 2020; Yu et al., 2020; Keyaers et al., 2020) y del gen viral diana en estudio. Es importante considerar en el modelo de análisis que los valores de Ct no poseen una distribución normal y que podrían covariar con los valores de Ct del transcripto de referencia 
Innovación y Desarrollo Tecnológico y Social (2020) 2 (2): 1-14- Número especial COVID-19

humano (Figura 2e). De esta manera, la determinación del número de copias del SARS-CoV-2 de la muestra procesada se estimará mediante el ingreso/análisis de los valores de $C t$ en un modelo integrado de ajuste en base a los factores previamente mencionados, mediante la implementación de una aplicación web (Figura 2f).

Está claro que ninguna modalidad diagnóstica es perfecta. Para obtener resultados de RT-qPCR confiables, cada paso del procedimiento en las etapas preanalítica, analítica y postanalítica debe realizarse satisfactoriamente. En la fase preanalítica es relevante garantizar los procedimientos para una adecuada recolección, transporte y conservación de las muestras. En la fase analítica es importante la inclusión de controles internos tanto en la extracción del ARN viral, como en la preparación de la RT-qPCR para poder detectar de manera temprana problemas de contaminación de muestras y/o insumos. Además, es muy importante la capacitación del personal para la lectura e interpretación de los resultados generados por la qPCR. Los resultados de la RT-qPCR se deben considerar junto a los datos epidemiológicos, observaciones clínicas y el historial del paciente para un diagnóstico apropiado.

\section{Financiamiento}

Este proyecto ha sido financiado por el Programa de Articulación y Fortalecimiento Federal de las Capacidades en Ciencia y Tecnología COVID-19 del Ministerio de Ciencia, Tecnología e Innovación de Argentina. (Proyecto BUE 21). 


\section{Agradecimientos}

Agradecemos el apoyo de la Facultad de Ciencias Médicas - UNLP y al CCT CONICET La Plata.

\section{Referencias bibliográficas}

Lupia, T., Scabini, S., Pinna, S.M., Di Perri, G., De Rosa, F.G., Corcione, S. (2020). 2019novel coronavirus outbreak: A new challenge. Journal of Global Antimicrobial Resistance, 21, 22-27. https://doi.org/10.1016/j.jgar.2020.02.021

Mahase, E. (2020) Covid-19: most patients require mechanical ventilation in first 24 hours of critical care. BMJ, 368:m1201. https://doi.org/10.1136/bmj.m1201

Rhee, C., Kanjilal, S., Baker, M., Klompas, M. (2020) Duration of SARS-CoV-2 Infectivity: When is it Safe to Discontinue Isolation? Clinical Infectious Diseases, ciaa1249. https://doi.org/10.1093/cid/ciaa1249

Chu, C.M., Poon, L.L., Cheng, V.C., Chan, K.S., Hung, I.F., Wong, M.M., Chan, K.H., Leung, W.S., Tang, B.S., Chan, V.L. y Ng, W.L. (2004) Initial viral load and the outcomes of SARS. CMAJ, 171 (11): 1349-1352. https://doi.org/10.1503/cmaj.1040398 Liu, Y., Yang, Y., Zhang, C., Huang, F., Wang, F., Yuan, J., Wang, Z., Li, J., Li, J., Feng, C. y Zhang, Z. (2020) Clinical and biochemical indexes from 2019-nCoV infected patients linked to viral loads and lung injury. Science China Life Sciences, 63 (3): 364-374. https://doi.org/10.1007/s11427-020-1643-8 
Innovación y Desarrollo Tecnológico y Social (2020) 2 (2): 1-14- Número especial COVID-19

Park, M., Won, J., Choi, B.Y. y Lee, C.J. (2020) Optimization of primer sets and detection protocols for SARS-CoV-2 of coronavirus disease 2019 (COVID-19) using PCR and real-time PCR. Experimental \& Molecular Medicine, 52 (6): 963-77. https://doi.org/10.1038/s12276-020-0452-7

Bustin, S. y Huggett, J. (2017) qPCR primer design revisited. Biomolecular Detection and Quantification, 14:19-28. https://doi.org/10.1016/j.bdq.2017.11.001

Li, D., Zhang, J. y Li, J. (2020) Primer design for quantitative real-time PCR for the emerging Coronavirus SARS-CoV-2. Theranostics, $10 \quad$ (16): 7150. https://doi.org/10.7150/thno.47649

Pan, Y., Zhang, D., Yang, P., Poon, L.L. y Wang, Q. (2020) Viral load of SARS-CoV-2 in clinical samples. The Lancet Infectious Diseases, 20 (4): 411-412. https://doi.org/10.1016/S1473-3099(20)30113-4

Yu, F., Yan, L., Wang, N., Yang, S., Wang, L., Tang, Y., Gao, G., Wang, S., Ma, C., Xie, R. y Wang, F. (2020) Quantitative detection and viral load analysis of SARS-CoV-2 in infected patients. Clinical Infectious Diseases, 71 (15), 793-798,. https://doi.org/10.1093/cid/ciaa345

Keyaerts, E., Vijgen, L., Maes, P., Duson, G., Neyts, J., Van Ranst, M. (2006) Viral load quantitation of SARS-coronavirus RNA using a one-step real-time RT-PCR. International Journal of Infectious Diseases, $10 \quad$ (1): 32-37. https://doi.org/10.1016/j.ijid.2005.02.003 